\title{
CARACTERIZAÇÃO DA ARBORIZAÇÃO COMO FERRAMENTA PARA IMPLANTAÇÃO DE CORREDORES ECOLÓGICOS URBANOS
}

\author{
CHARACTERIZATION OF URBAN AFFORESTATION AS A TOOL FOR THE \\ IMPLEMENTATION OF ECOLOGICAL CORRIDORS
}

\author{
Paula de Souza Nobre ${ }^{1}$ e Fernando Antonio Bataghin ${ }^{2}$
}

\begin{abstract}
RESUMO
Nos ambientes urbanos, o crescimento desordenado aliado a falta de gestão pode trazer consequências permanentes à população e impactos ambientais negativos como uso desordenado de solo, redução da disponibilidade hídrica e da qualidade atmosférica, e dificuldades na conservação das áreas verdes. $O$ objetivo deste trabalho foi caracterizar a arborização urbana no município de Jaboticabal, identificando os possíveis conflitos e inadequações no manejo com vista a implantação de corredores ecológicos urbanos como parte do Projeto Piloto de Floresta Urbana, Programa do Município Verde Azul do Estado de São Paulo. A área de estudo elencada está inserida na cidade de Jaboticabal-SP, realizando-se o diagnóstico da arborização urbana por meio de da caracterização conflitos e necessidades de manejo. Na arborização urbana, 49,19\% dos indivíduos apresentaram dano físico relacionado à poda, sugerindo-se a necessidade de poda para $27,69 \%$ e a remoção do espécime para $7,82 \%$ dos casos, quando observada a morte iminente do vegetal, fitossanidade ruim ou risco de queda. De forma geral, a área selecionada apresenta baixo índice de conflitos e questões relacionadas à manejo, parâmetros que indicam potencial para implantação de um corredor ecológico urbano e consolidação do Projeto Piloto de Floresta Urbana.
\end{abstract}

Palavras-chave: Cidade; Conflitos; Floresta Urbana; Planejamento Ambiental.

\begin{abstract}
In urban environments, disordered growth combined with lack of management can bring permanent consequences to the population and negative environmental impacts such as disorderly land use, reduced water availability and atmospheric quality, and difficulties in the conservation of green areas. The objective of this study was to characterize the urban afforestation in the municipality of Jaboticabal, identifying the possible conflicts and inadequacies in the management with a view to the implementation of urban ecological corridors as part of the Urban Forest Pilot Project, Program of the Verde Azul Municipality of the State of São Paulo. The study area is located in the city of Jaboticabal-SP, with the diagnosis of urban afforestation through the characterization of conflicts and management needs. In urban afforestation, $49.19 \%$ of the individuals had physical damage related to pruning, suggesting the need for pruning for $27.69 \%$ and the removal of the specimen for $7.82 \%$ of cases, when the imminent death of the plant is observed, poor plant health or fall risk. In general, the selected area has a low rate of conflicts and issues related to management, parameters that indicate a potential for the implementation of an urban ecological corridor, and consolidation of the Urban Forest Pilot Project.
\end{abstract}

Keywords: City; Conflicts; Urban Forest; Environmental Planning.

Recebido em 27.01.2021 e aceito em 03.08.2021

1 Graduada em Ciências Biológicas e Gestão Ambiental. Discente na FATEC Jaboticabal/SP. Email: paulasnobre@hotmail.com

2 Graduado em Ciências Biológicas. Doutor em Ecologia e Recursos Naturais. Docente na FATEC Jaboticabal/SP. Email: bataghin@gmail.com 


\section{INTRODUÇÃO}

O desenvolvimento do ser humano sempre esteve relacionado com o meio inserido seja com a utilização dos recursos naturais ou alterações da paisagem. Em ambientes urbanos, o crescimento desordenado aliado com a falta de gestão e gerenciamento podem trazer consequências permanentes à população e impactos negativos ao meio ambiente.

Com o crescimento populacional nos centros urbanos, multiplicam-se os problemas relacionados à falta de planejamento e estrutura para suportar a demanda por espaço e recursos (GRISE; BIONDI; ARAKI, 2016). Esses recursos podem estar relacionados ao uso e ocupação de solo, disponibilidade hídrica, manutenção da qualidade atmosférica e manejo e conservação das áreas verdes.

A arborização urbana pode ser definida como o conjunto da vegetação arbórea e arbustiva, natural ou cultivada, distribuída nas vias públicas de uma cidade (ANDREATTA et al., 2011), podendo o conceito ser complementado com o ato de incluir espécies vegetais nos espaços viários com objetivo de ornamentar o ambiente urbano e regular o ciclo hidrológico do local, bem como beneficiar a população com melhorias na qualidade de vida (BENATTI et al., 2012).

Milano (1988) indica em seu trabalho que tanto a arborização de ruas como as áreas verdes estão incluídas na definição de arborização urbana. Ainda de forma contemporânea e moderna e adotando uma nova ótica aos estudos ambientais urbanos, o conceito de arborização urbana poderia ser utilizado, de maneira ampla, para designar as florestas urbanas (BIONDI, 2015).

A presença de uma arborização urbana bem planejada produz serviços ecossistêmicos que desempenham papel fundamental para a manutenção da qualidade ambiental, trazendo benefícios tanto para a saúde humana como para a conservação da biodiversidade e pode configurar-se como importante elemento no processo de implementação de um projeto urbano em direção à sustentabilidade. Além disso, contribuem para minimizar o aquecimento global, desde que considere as necessidades da população, o contexto local e as características das espécies a serem plantadas, de forma a cumprir sua função socioambiental (CEMIG, 2011).

Os avanços positivos microclimáticos são consequências da redução da poluição, e por esse motivo, são bastante cotados quando se tem um projeto de arborização de uma área, tendo em vista que a presença das espécies arbóreas, além de realizar o mecanismo de filtragem dos gases atmosféricos, como já conhecido, podem ser responsáveis pelo bem-estar social da população (BENATTI et al., 2012).

Dentre todos os serviços ecossistêmicos citados a respeito da arborização urbana, talvez o mais perceptível seja o conforto ambiental que os ambientes arborizados oferecem, 
especialmente, em relação a temperatura e umidade. Basso e Corrêa (2014), explicam que as folhas de uma árvore possuem baixo índice de reflexão e com isso conseguem absorver a radiação solar incidente e bloquear significativamente a quantidade da radiação solar direta, diminuindo o calor irradiado, a temperatura ao redor e, possibilitando, a criação de microclimas urbanos diferenciados por meio do sombreamento, da redução da velocidade dos ventos, da proteção solar do conjunto urbano edificado e pela redução das temperaturas urbanas com a evapotranspiração e retenção de umidade do solo e do ar.

Todo o conjunto da vegetação urbana presente nos ambientes urbanos, bem como a sua quantidade, tipificação e distribuição que influenciam nas funções ecológicas, estéticas e sociais podem ser classificadas como Floresta Urbana (GRISE; BIONDI; ARAKI, 2016). No termo Floresta Urbana, seguindo a definição de Biondi (2015), estaria incluso Florestas Urbanas Particulares (bosques e jardins residenciais) e Florestas Urbanas Públicas (arborização viária e áreas verdes).

A fragmentação florestal é responsável por influenciar a composição genética das populações e dessa forma, reduz a sua variabilidade, a capacidade adaptativa das espécies, levando em sua extinção pelo isolamento (OLIVEIRA et al., 2016). Como ressaltado por Pereira e Cestario (2016) o conceito de corredor ecológico está pautado, principalmente na ideia de conexão entre remanescentes florestais, visando a manutenção ou aumento da biodiversidade, a partir da redução de seu isolamento, dessa forma, pode-se considerar a proteção da biodiversidade como um objetivo social, devido aos benefícios que pode fornecer à sociedade, através da sua influência positiva sobre a qualidade da água, do ar e da saúde humana.

O Programa Munícipio Verde Azul idealizado pela Secretaria de Infraestrutura e Meio Ambiente do Governo do Estado de São Paulo em 2007, preconiza na diretiva de Arborização Urbana que os munícipios paulistas desenvolvam, executem e dê publicidade ao um Projeto Piloto de Floresta Urbana, defendendo que as áreas verdes, independentes se são propriedades do setor público ou privado, podem ser interligadas e agregadas aos elementos físicos urbanos, sendo sujeitas a função do espaço, população biológica, valores socioeconômicos e condições geoambientais (SÃO PAULO, 2011). Além disso, o documento ressalta ainda que, fragmentos de vegetação associados a uma floresta urbana podem mitigar a poluição química e sonora, reduzir o efeito de ilha de calor, aumentar a disponibilidade e qualidade da água, reduzir a erosão nas encostas e, por consequência, os assoreamentos dos rios.

A utilização da arborização urbana para a implantação de corredores ecológicos urbanos para a manutenção dos remanescentes florestais mostra-se um caminho interessante e promissor para a aplicação do conceito de florestas urbanas. O conhecimento da arborização urbana é fundamental para o entendimento das questões ligadas ao manejo das espécies 
elencadas para o plantio e falhas nesse processo são os fatores que mais influenciam a geração de conflitos com a infraestrutura urbana, proliferação de pragas e diminuição da estimativa de vida dos exemplares.

Dessa forma, o trabalho visa caracterizar a arborização urbana no município de Jaboticabal, em vias, canteiros e pequenas praças definidas, identificando possíveis conflitos e inadequações de manejo, para que seja possível propor um modelo de corredores ecológicos urbanos que integre quatro áreas verdes do perímetro urbano no município. Assim, o trabalho apresenta-se como ferramenta de qualificação e quantificação dos parâmetros necessários para a implantação do Projeto Piloto de Floresta Urbana, como preconizado pelo Programa do Município Verde Azul.

\section{MATERIAL E MÉTODOS}

\section{Área de estudo}

A área de estudo compõe-se de uma amostra pertence a cidade de Jaboticabal, São Paulo, com população estimada de 71662 habitantes e área de 706,602 km2, de acordo com o censo mais recente realizado pelo IBGE (2010). Apresenta altitude de 595 metros acima do nível do mar e coordenadas geográficas $21^{\circ} 15^{\prime} 20^{\prime \prime}$ de latitude Sul e 48¹9'16" de longitude Oeste.

Para realizar-se o diagnóstico e a caracterização da vegetação viária, canteiros e praças foi necessário o levantamento de dados quali-quantitativos por meio de inventário. A área selecionada com potencial para a implantação de corredor ecológico e contribuição para a formação da floresta urbana foi selecionada com o objetivo de integrar os instrumentos urbanos e áreas verdes, promovendo dessa maneira, a recuperação de regiões fragilizadas, como as próximas a recursos hídricos e conservação da biodiversidade (figura 1). Todas as vias que compõe a área selecionada foram avaliadas com a coleta de dados no período de janeiro a março de 2020 


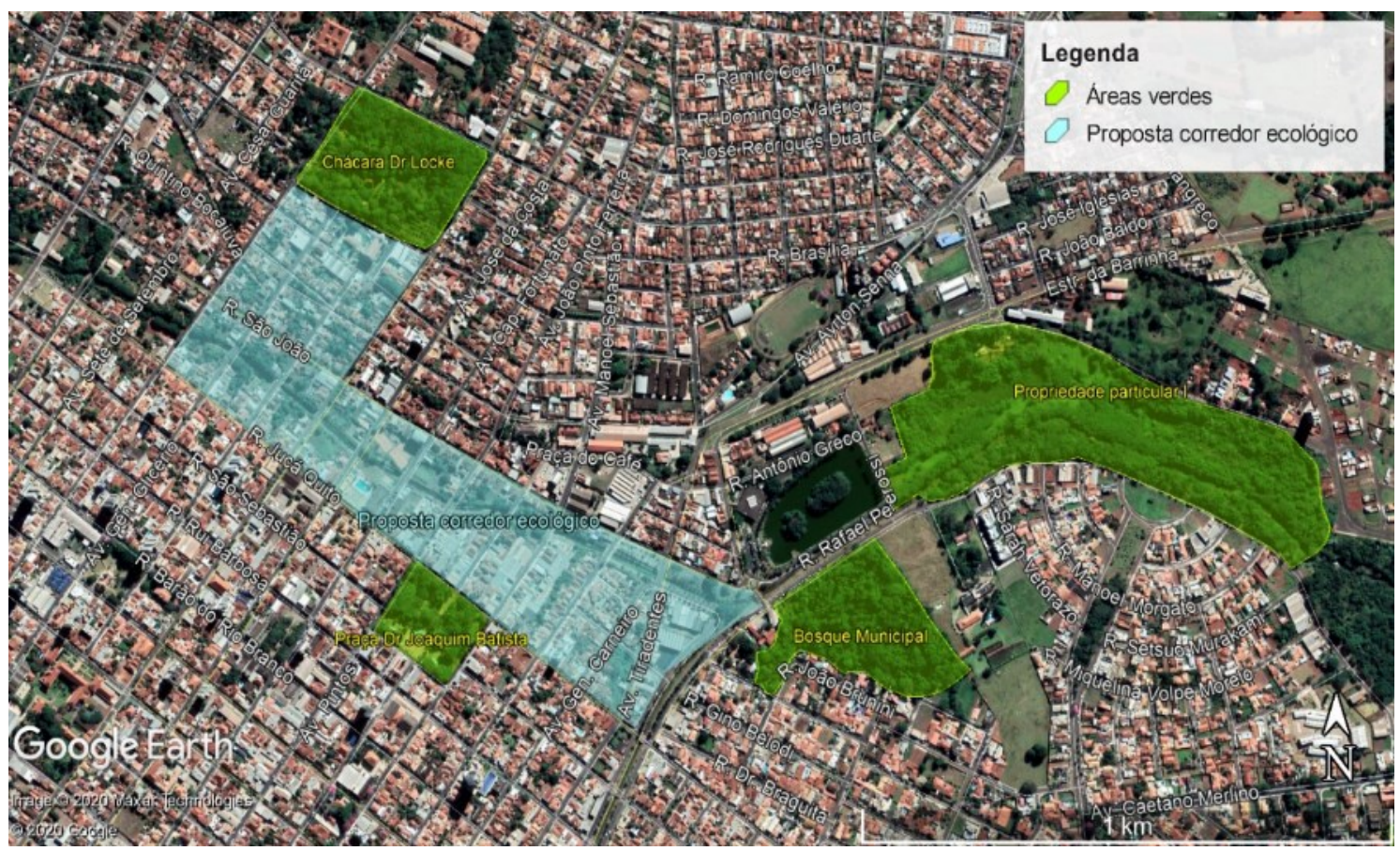

Fonte: Google Earth (2020)

Figura 1. Região selecionada no município de Jaboticabal, SP para a caracterização da arborização urbana e possível implantação do corredor ecológico

Figure 1. The selected region in the municipality of Jaboticabal, SP for the characterization of urban afforestation and possible implementation of the ecological corridor

A área selecionada para o levantamento de dados quali-quantitativos, em relação a arborização urbana, foi escolhida com o objetivo de integrar áreas verdes para construção de corredores ecológicos no meio urbano e a conservação dos recursos hídricos, como preconizado no Programa Município Verde Azul do Estado de São Paulo, na diretiva sobre Arborização Urbana para o desenvolvimento do Projeto Piloto de Florestas Urbanas. A extensão inventariada totalizou 7,42 quilômetros, sendo composta pelas vias: Avenida Carlos Berchieri, Rua dos Expedicionários, Travessa General Osório, Avenida Tiradentes, Avenida General Carneiro, Avenida Duque de Caxias, Avenida Major Novaes, Avenida Bento Vieira, Avenida Pintos, Avenida Benjamin Constant, Avenida José da Costa, Avenida Paulino Braga, Avenida do Carmo/Liberato Costa Fontes, Avenida General Glicério/Basiliano Costa Fontes, Avenida Professor Vicente Quirino, Rua Dr. Locke, Rua José Bonifácio, Rua Quintino Bocaiúva, Rua São João, Rua Juca Quito e Praça Quintino Bocaiúva.

Em campo, as medidas foram registradas com auxílio de fita métrica de 1,5 metros e trena a laser $\mathrm{BOSCH} \otimes$ GLM 40, digitadas posteriormente em planilha do Microsoft Office Excel $尺$ 2013. Na figura 2 é exemplificado a nomenclatura construída e os parâmetros qualitativos e quantitativos utilizados, bem como as variáveis estabelecidas para a coleta de dados baseados na literatura (LESSI; BATAGHIN; PIRES, 2017a; SILVA; GONÇALVES; PAIVA, 2017). 


\begin{tabular}{cl}
\hline & \multicolumn{1}{c}{ Nomenclatura } \\
\hline Parâmetros & \multicolumn{1}{c}{ Descrição das variáveis } \\
\hline \multirow{3}{*}{ Porte } & Altura total $(\mathrm{H})$ : altura total do vegetal, em metros. Altura da primeira \\
& bifurcação $(\mathrm{HB})$ : referente à altura da primeira bifurcação do tronco no vegetal \\
& em metros. Diâmetro à altura do peito (DAP): medida em centímetros do \\
& diâmetro do tronco da árvore a altura de 1,3 metros.
\end{tabular}

\section{Posicionamento do plantio}

Fitossanidade

Podas

Distância do meio fio (MF): distância em metros a partir do meio fio da calçada até o tronco da árvore. Distância da construção $(\mathrm{CT})$ : distância em metros a partir da construção até o tronco da árvore. Área livre permeável $(A L)$ : mensuração em metros quadrados $\left(\mathrm{m}^{2}\right)$ da área disponível para o crescimento da árvore, considerando-se 0 para a ausência de área livre, 1 para áreas menores que $1 \mathrm{~m}^{2}, 2$ para áreas de 1 a $2 \mathrm{~m}^{2}$ e 3 para áreas maiores que $2 \mathrm{~m}^{2}$.

Determinação do estado geral do indivíduo de acordo com sua integridade, estabelecendo-se 0 para indivíduos com morte iminente (morta), 1 em estágio de declínio (estágio ruim), 2 com pequenos danos ou problemas de pragas (estágio regular) e 3 vigorosos e sem pragas (estágio bom).

A necessidade de poda foi sugerida se o vegetal apresentasse algum conflito, determinando-se 0 para casos sem necessidade e 1 para casos que necessitavam da realização de poda.

Dano Físico

Causado por Poda (DFP)

Para os danos físicos causados por poda atribuiu-se 0 para a ausência de danos e 1 para a presença de danos.

Sempre foi sugerida em casos de riscos iminentes de queda e em estágio de declínio ou mortas, parâmetros avaliados na fitossanidade e, relacionando-se, com a presença de conflitos, danos físicos causado por poda e plantios de espécies inadequadas para o ambiente urbano. Assim, foi atribuído 0 quando não era necessário a remoção do indivíduo e 1 para casos de remoção.

espécime

Natureza da espécie (NE)

Determinada após a identificação das espécies, classificando-se como 0 para as nativas da região, 1 para as nativas do Brasil, 2 para as espécies exóticas e 3 para as exóticas invasoras e, quanto a sua tipologia, 0 para espécies arbóreas, 1 para espécies arbustivas e 2 para palmeiras.

Nota: Elaborado pelos autores (2020) com base em Lessi, Bataghin, Pires (2017a) e Silva, Gonçalves, Paiva (2017).

Figura 2. Descrição dos parâmetros e suas variáveis determinados para a construção do inventário

Figure 2. Description of the parameters and their variables determined for the construction of the inventory

Em relação a natureza da espécie (NE), sua classificação foi determinada após a identificação da espécie, a qual seguiu os procedimentos usuais para este tipo levantamento (FIDALGO; BONONI, 1989). A identificação do material foi realizada com o auxílio de literatura especializada, por comparação com material já depositado em herbários da região ou por consulta a especialistas. A validade e grafia dos nomes das espécies foi verificada nos sites especializados: w3Tropicos (www.tropicos.org) e ePIC (www.rbgkew.org.uk/epic) sendo utilizadas as abreviaturas dos autores sugeridas por Brummitt e Powell (1992). As espécies com potencial de invasão foram verificadas com base nos dados disponibilizados pelo Instituto Hórus (INSTITUTO HÓRUS, 2020). Após a identificação, as espécies foram classificadas de acordo com a nomenclatura adotada na figura 2 . 


\section{RESULTADOS E DISCUSSÃO}

No levantamento realizado na área selecionada, com potencial para implantação de corredor ecológico na cidade de Jaboticabal-SP, foram encontradas 44 espécies pertencentes a 24 famílias botânicas somando no total 307 exemplares. Entre as áreas inventariadas, a Avenida Carlos Berchieri, Travessa General Osório e Avenida Major Novaes não apresentaram vegetação.

A maioria das espécies escolhidas para a arborização urbana de Jaboticabal-SP são arbóreas, com 282 indivíduos (91,86\%), encontrando-se em menor proporção, 5,86\% de espécies arbustivas $(\mathrm{N}=18)$ e $2,28 \%$ de palmeiras $(\mathrm{N}=7)$. Em levantamento realizado no município de Silveira Martins no Rio Grande do Sul, em 2011, foi encontrado uma proporção de $65 \%$ para as espécies arbóreas, $23,5 \%$ para espécies arbustivas e $11,5 \%$ de palmeiras (BACKES et al., 2011).

A utilização de espécies na arborização urbana, por vezes revela um conflito entre a questão estética desta e a questão de manutenção de um equilíbrio ecológico, como por exemplo, à redução da propagação de pragas e doenças. Dessa forma, é possível com a presença de uma quantidade diversificada de árvores no ambiente urbano, atrair a fauna das áreas naturais periféricas, como insetos e aves, aumentando assim a taxa de polinização e de produção de frutos (ANDRADE; JERONIMO, 2015).

Em relação à altura total (figura $3 \mathrm{~A}$ ), observou-se a predominância de indivíduos com até 5 metros de altura $(52,44 \%, N=161)$ e para os maiores de 5 metros, com até 10 metros $42,67 \%(N=131)$. Em menor proporção foram encontradas árvores com mais de 10 metros $(4,56 \%, N=14)$ e apenas 1 indivíduo com mais de 15 metros $(0,33 \%)$. A média da altura permaneceu em 5,26 metros com mínima de 0,43 e máxima de 16 metros.

É importante o conhecimento da altura máxima que atingirá a espécie escolhida para o plantio em vias públicas para que se minimizem os conflitos gerados e a manutenção no decorrer do seu desenvolvimento. Associado com a altura da primeira bifurcação, essas variáveis são importantes para que não haja transtornos futuros em relação a utilização das vias pelos pedestres. As mudas escolhidas para serem plantadas em vias públicas deverão possuir características mínimas, como altura de 2,5 metros, DAP de $0,03 \mathrm{~m}(3 \mathrm{~cm})$, altura da primeira bifurcação de 1,8 metros, estar isenta de pragas e doenças e apresentar sistema radicular bem formado e consolidado na embalagem (SÃO PAULO, 2005). 


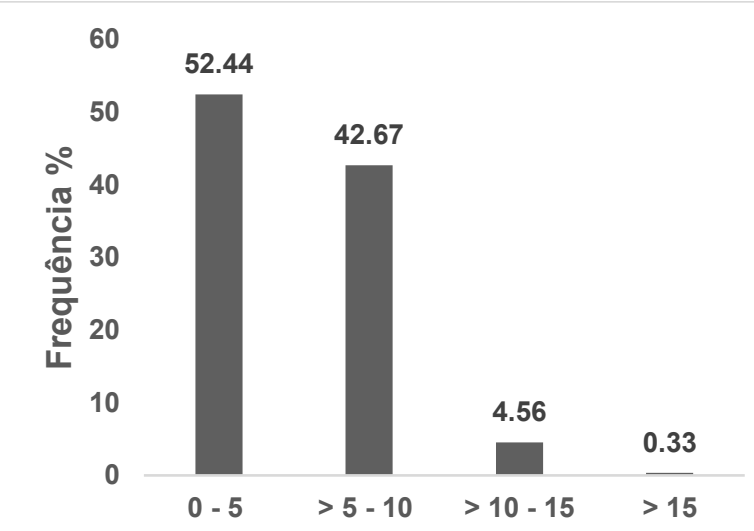

A

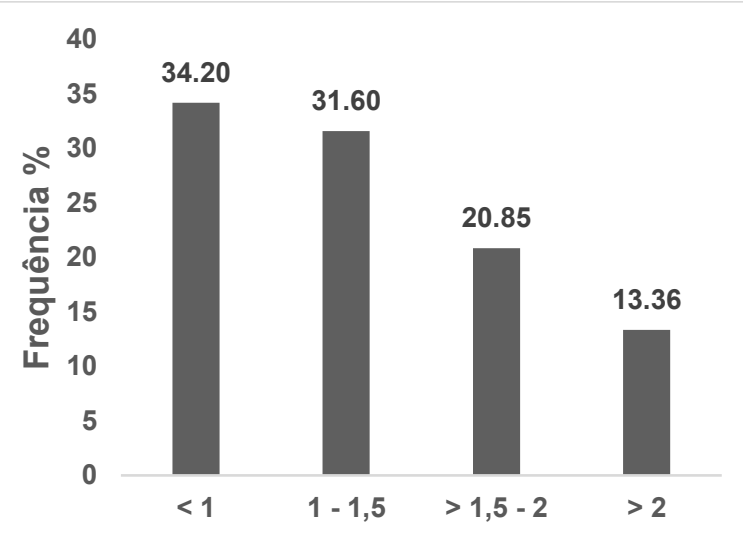

B

Altura da Primeira Bifurcação (m)

Figura 3. Frequências percentual das variáveis relacionadas ao porte da arborização em Jaboticabal, SP. (A) frequência das classes quantificadas em altura total e (B) altura da primeira bifurcação mensurado em metros

Figure 3. Percentual frequencies of the variables related to the size of afforestation in Jaboticabal, SP. (A) frequency of the classes quantified in total height and $(B)$ height of the first bifurcation measured in meters

Na figura 3B é apresentada a quantificação da altura da primeira bifurcação, observase que $34,4 \%(N=105)$ apresentam bifurcação menor que 1 metro de altura, 31,6\% $(N=97)$ com altura da primeira bifurcação entre 1 e 1,5 metros, e em menor proporção, 20,85\% ( $N=64)$ indivíduos com altura maior que 1,5 até 2 metros e 13,36\% $(\mathrm{N}=41)$ com mais de 2 metros. A média permaneceu em 1,31 metros com mínima de 0,05 e máxima de 6,6 metros. Os indivíduos com a primeira bifurcação inferior a 1,5 metros apresentam maior potencial para conflitos com o trânsito de pessoas e/ou veículos. Segundo o Manual Técnico de Arborização Urbana de São Paulo e já citado acima, as mudas escolhidas para serem plantadas em vias públicas deverão possuir altura da primeira bifurcação de 1,8 metros, o que minimiza os potenciais conflitos com outros elementos urbanos (SÃO PAULO, 2005).

Os dados referentes ao diâmetro à altura do peito (DAP) em centímetros $(\mathrm{cm})$ e da área da copa em metros quadrados $\left(\mathrm{m}^{2}\right)$ mostram a maior frequência de indivíduos com DAP de até $20 \mathrm{~cm},(44,63 \%$ e $\mathrm{N}=137)$, seguido de $37,46 \%(\mathrm{~N}=115)$ para indivíduos com DAP maior de 20 $40 \mathrm{~cm}$ (figura 4). A média permaneceu em 25,6 cm, com máximo de $124 \mathrm{~cm}$ e mínimo de $1 \mathrm{~cm}$. 


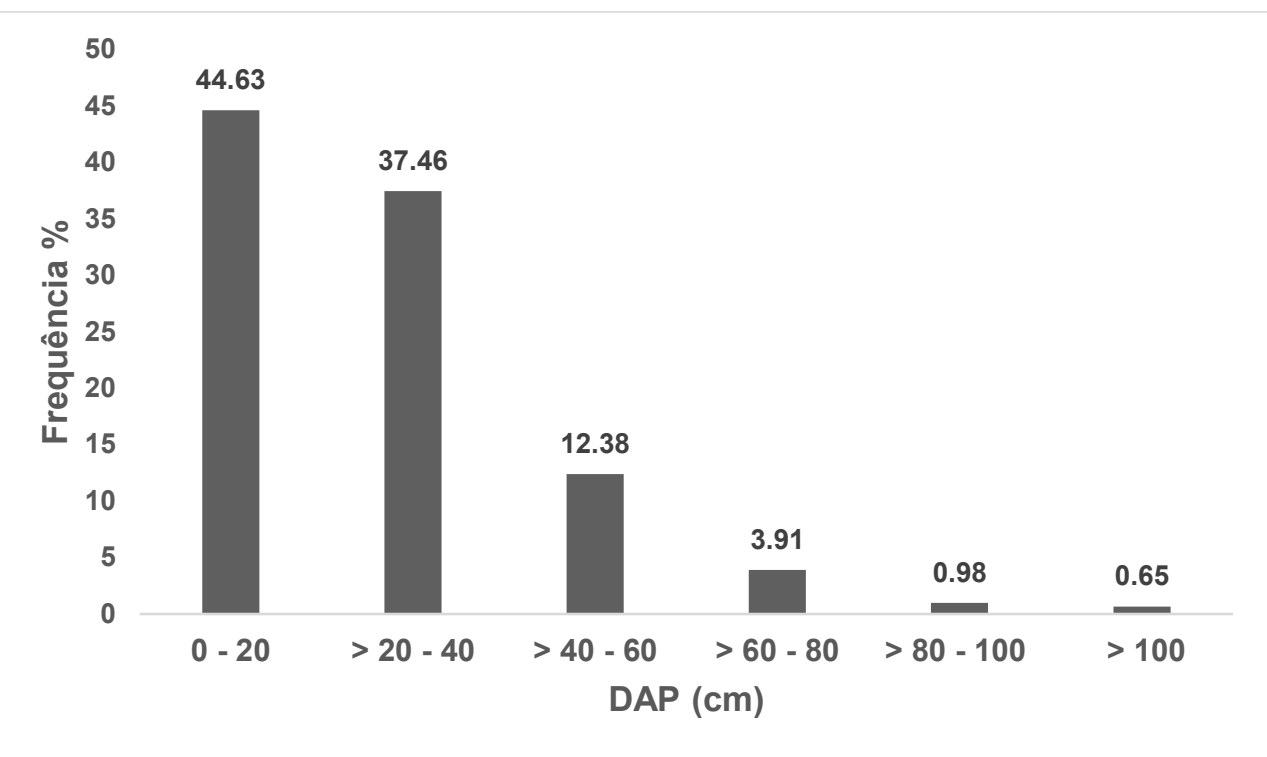

Figura 4. Frequências percentuais das variáveis relacionadas ao porte da arborização em Jaboticabal, $\mathrm{SP}$, referente a frequência das classes quantificadas do diâmetro à altura do peito (DAP) em centímetros

Figure 4. Percentual frequency of variables related to the size of afforestation in Jaboticabal, SP, referring to the frequency quantified classes of diameter at breast height $(\mathrm{DBH})$ in centimeters

A medida do diâmetro do tronco à altura do peito (DAP) é uma informação importante para o conhecimento do porte da árvore e de sua idade (jovem ou adulta), não devendo ser analisado isolado, mas em conjunto com a altura total e diâmetro da copa. Tratando-se de um inventário contínuo é uma medida importante para acompanhar o desenvolvimento dos indivíduos arbóreos e estimar o espaço ocupado ao longo do tempo da área de passeio (SILVA; PAIVA; GONÇALVES, 2017). Além disso, o DAP médio da espécie quando adulta pode ser utilizado como critério de seleção de mudas para plantio em locais determinado segundo as características disponibilidade de área livre permeável e da proximidade do local de implantação com outros elementos do ambiente urbano.

As mensurações de altura e diâmetro a altura do peito (DAP) se correlacionam, pois, quanto maior o porte do indivíduo maior será sua altura e, consequentemente, o diâmetro à altura do peito. Assim, uma arborização com árvores de grande porte traz mais benefícios ao ambiente urbano, na qual todas suas funções serão maximizadas, como transpiração, sequestro e estoque de carbono, sombreamento, minimização da poluição e influência sobre o clima urbano. Por outro lado, quando as árvores são extremamente grandes torna-se difícil o manejo, como a retirada de galhos secos, podas e com risco maior de danos em uma possível queda (LESSI; BATAGHIN; PIRES, 2017b), além de aumentar a possibilidade de conflitos com outros elementos urbanos, como trânsito, iluminação, edificações, entre outros.

Os conflitos com as raízes (figura $5 \mathrm{~A}$ ) foram constatados em $47,88 \%$ dos indivíduos. Em $52,12 \%(N=160)$ dos indivíduos amostrados as raízes estavam totalmente subterrâneas; 
$13,68 \%(N=42)$ com raízes visíveis na área livre permeável; $23,13 \%(N=71)$ com raízes provocando rachaduras visíveis na calçada e $11,07 \%(\mathrm{~N}=34)$ já apresentavam raízes que destruíram complemente as calçadas. Em relação aos conflitos relacionados com a fiação elétrica (figura 5B), 57\% ( $N=175)$ não apresentavam conflitos, $1,3 \%(N=4)$ a fiação elétrica estava abaixo da copa da árvore, 13,03\% (N=40), apresentavam fiação elétrica no meio da copa e $28,66 \%(N=88)$ apresentavam fiação elétrica acima da copa. Os conflitos presentes com as espécies vegetais e as edificações, a iluminação, área de passeio, com a sinalização de trânsito e com outras árvores (figura $5 \mathrm{C})$ apresentaram frequência de $19,54 \%(\mathrm{~N}=60), 5,86 \%(\mathrm{~N}=18)$, $9,45 \%(N=29), 1,95 \%(N=6)$ e $17,92 \%$, $(N=55)$, respectivamente.

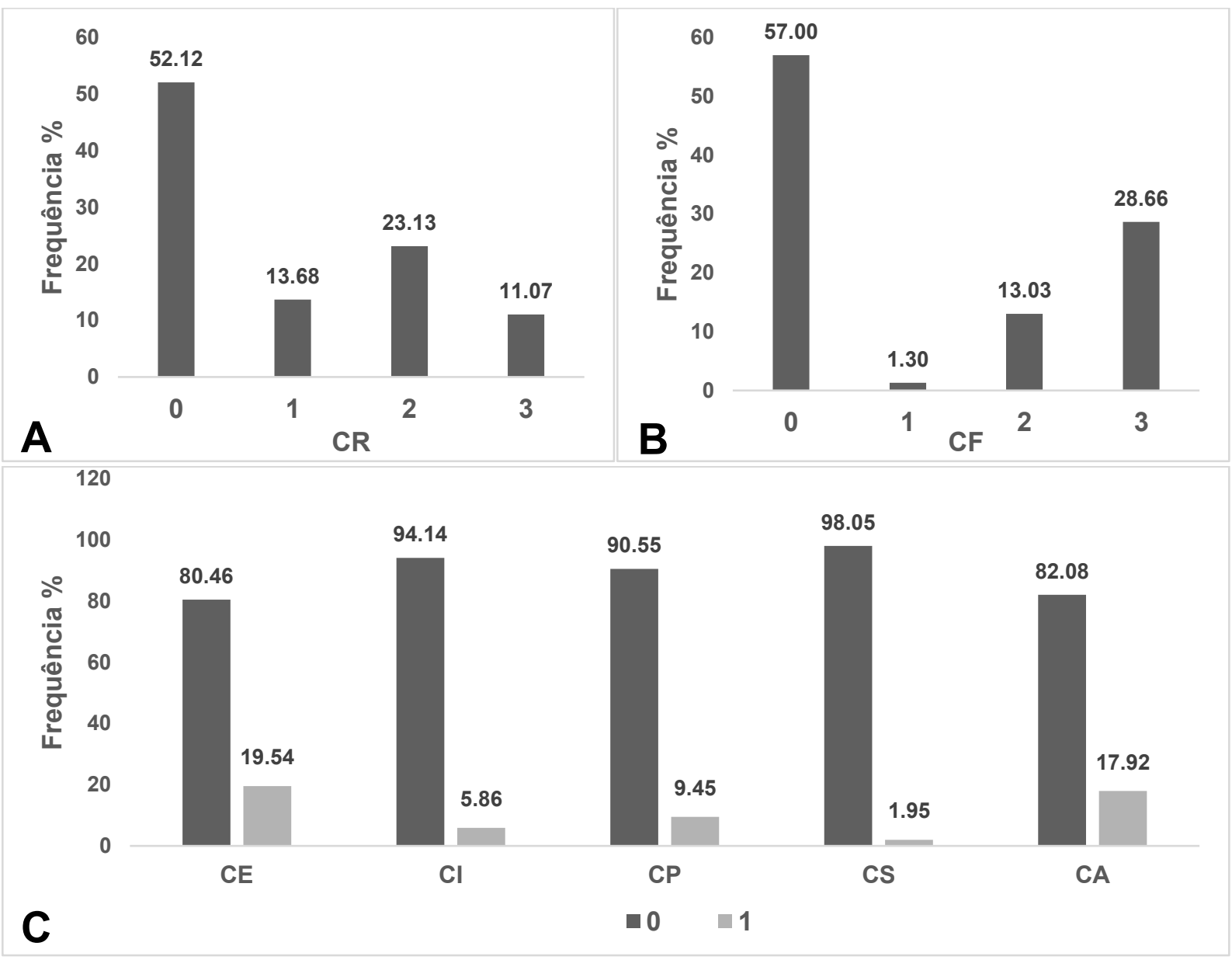

Figura 5. Frequência percentual dos conflitos quantificados. A) Conflitos relacionados a raiz (CR) - 0 : ausência, 1: raiz visível na área de crescimento, 2: visíveis rachaduras na calçada e 3: calçada destruída; B) Conflitos em relação a fiação elétrica (CF) - 0: ausência, 1: fiação abaixo da copa, 2: fiação no meio da copa e 3: fiação acima da copa; C) ausência (0) ou presença (1) de conflitos relacionados a edificação $(C E)$, iluminação $(C I)$, área de passeio $(C P)$, sinalização $(C S)$ e com outras árvores (CA)

Figure 5. Percentual frequency of quantified conflicts. A) Conflicts related to roots (CR) - 0 : absence, 1 : visible roots in the growth area, 2: visible cracks in the sidewalk and 3: destroyed sidewalk; B) Conflicts related to electric wiring (CF) - 0 : absence, 1 : wiring below the canopy, 2: wiring in the middle of the canopy and 3: wiring above the canopy; C) absence (0) or presence (1) of conflicts related to the building $(\mathrm{CE})$, lighting $(\mathrm{Cl})$, walkway area $(\mathrm{CP})$, signaling $(\mathrm{CS})$ and with other trees (CA) 
Quando analisados isoladamente pode-se presumir que frequência de conflitos encontradas nos indivíduos quantificados é baixa, porém, foi observado a presença de vários conflitos em apenas um indivíduo, comprometendo muitas vezes sua integridade e fitossanidade (figura 6A). A ausência planejamento, manejo e gerenciamento associado com a falta de uma legislação específica e o uso de espécies vegetais inadequadas, colabora para uma má qualidade na arborização urbana e espaços verdes, contribuindo para o surgimento de problemas nas estruturas físicas das edificações, tubulações e rede elétrica (CRISPIM et al., 2014). Assim, para Silva e Souza (2018), a falta de um planejamento adequado de ocupação urbana, além de trazer problemas ambientais, também interferem diretamente na qualidade de vida dos cidadãos (figura 6B).

Gracioli (2011), ressalta ainda que um dos principais desafios é interromper o processo de degradação ambiental nas áreas urbanas. Neste sentido, a criação, a recuperação, a qualificação dos espaços públicos e de convivência, são fundamentais a sustentabilidade, à valorização da paisagem, à parceria entre instituições públicas e privadas, assim como à melhoria das condições de conforto ambiental.

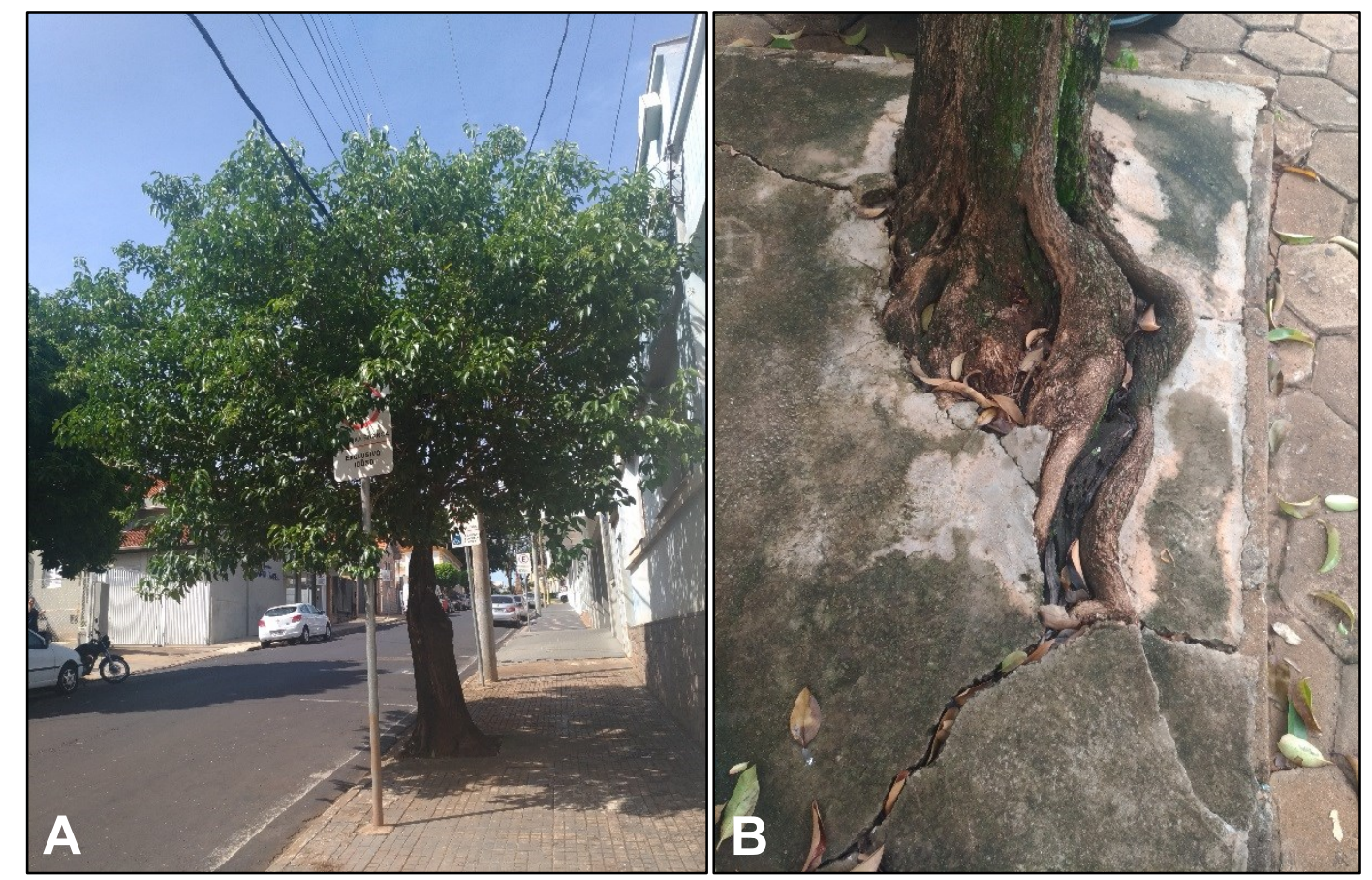

Figura 6. Em (A) indivíduo apresentando conflitos com a fiação elétrica, com a sinalização e edificação e em (B) conflito com a raiz com destruição da calçada por ausência de área livre permeável.

Figure 6. In (A) individual presenting conflicts with the electric wiring, with signaling and the building and in (B) conflict with the root with destruction of the sidewalk due to the absence of permeable free area 
A distância do meio fio (MF) predominante foi de até 0,5 metro, sendo observada em $75,57 \%$ dos indivíduos ( $\mathrm{N}=232)$, seguidos em de $14,66 \%(\mathrm{~N}=45)$ para distâncias maiores de $0,5$ até 1 metro, 2,28\% ( $N=7)$ para maiores de 1 metro até 2 metros e 7,49 $(\mathrm{N}=23)$ para distâncias maiores de 2 metros. A média da distância do meio fio permaneceu em 0,64 metro com máxima de 4,7 metros e mínima de 0,05 metro (figura 7A).

A distância da construção $(\mathrm{CT})$ teve sua maior proporção em medidas maiores que 2 metros, com 48,86\% ( $\mathrm{N}=150)$. As demais classes apresentaram um decréscimo respectivamente, mostrando que as áreas de passeio na área inventariada apresentam bom espaçamento para a passagem de pedestres, sendo dificultada apenas na presença de conflitos da raiz em casos de destruição do calçamento. Assim observou-se a frequência percentual de $24,43 \%(N=75)$ para distâncias maiores que 1,5 até 2 metros, 19,87\% $(N=61)$ para maiores que 1 metro até 1,5 metros e $6,84 \%(N=21)$ para espaçamentos até 1 metro. A média permaneceu em 1,83 metros com máxima de 2,94 metros e mínima de 0,36 metro (figura 7B).

Em relação a presença de área livre permeável $(A L)$, o maior percentual foi observado para áreas menores que $1 \mathrm{~m}^{2}$, apresentando $67,43 \%(\mathrm{~N}=207)$, seguindo de $19,54 \%(\mathrm{~N}=60)$ para indivíduos com ausência de $\mathrm{AL}$, com calçamento até o colo da planta, $8,47 \%(\mathrm{~N}=26)$ para áreas maiores que $2 \mathrm{~m}^{2}$ e 4,56\% ( $\left.\mathrm{N}=14\right)$ para áreas entre 1 e $2 \mathrm{~m}^{2}$. A média permaneceu em $0,33 \mathrm{~m}^{2}$ com máxima de 2,66 $\mathrm{m}^{2}$ e mínima de $0,06 \mathrm{~m}^{2}$ (figura $7 \mathrm{C}$ ).

As distâncias de construções, como o mobiliário urbano (bancas, cabines, guaritas, telefones) e do meio fio são importantes mensurações no inventário para se determinar se há conflitos nas vias públicas ou na área de passeio dos pedestres. $O$ distanciamento de construções e outros elementos urbanos depende das características da espécie selecionada, sobretudo as condições de desenvolvimento de raízes e copas, e vai desde a recomendação de não plantio até a distância de 12 metros (SÃO PAULO, 2005; LESSI; BATAGHIN; PIRES, 2017b). A área livre permeável disponível está interligada com as chances do vegetal em sobreviver e desenvolver-se saudavelmente, uma vez que essa área influencia na ciclagem de nutrientes, aeração do solo e na infiltração de água para as raízes (SÃO PAULO, 2005; SAMPAIO; ANGELIS, 2008).

O “espaço árvore”, uma área permeável destinada à implantação de uma muda arbórea de grande ou médio porte deve ter largura mínima para sua implantação. Em calçadas com no mínimo de 2 metros, a instalação de canteiros de 0,80 por 1,60 metros trazem muitas vantagens ambientais, como o aumento de área para infiltração da água no solo, minimização dos problemas relacionados à impermeabilização em função do solo, infiltração da água da chuva no solo, aumento da fixação da base da árvore, reabastecimento do lençol freático e embelezamento da cidade (SÃO PAULO, 2011). Esta área permeável em volta das árvores plantadas, pode ser sob a forma de canteiro, faixa ou piso drenante, com dimensões 
recomendadas, sempre que as características dos passeios ou canteiros centrais o permitirem, de $2,0 \mathrm{~m}^{2}$ para árvores de copa pequena (diâmetro em torno de 4,0 metros) e de $3,0 \mathrm{~m}^{2}$ para árvores de copa grande (diâmetro em torno de 8,0 metros) com espaço livre mínimo para o trânsito de pedestre em passeios públicos deverá ser de 1,20 metros (SÃO PAULO, 2005).

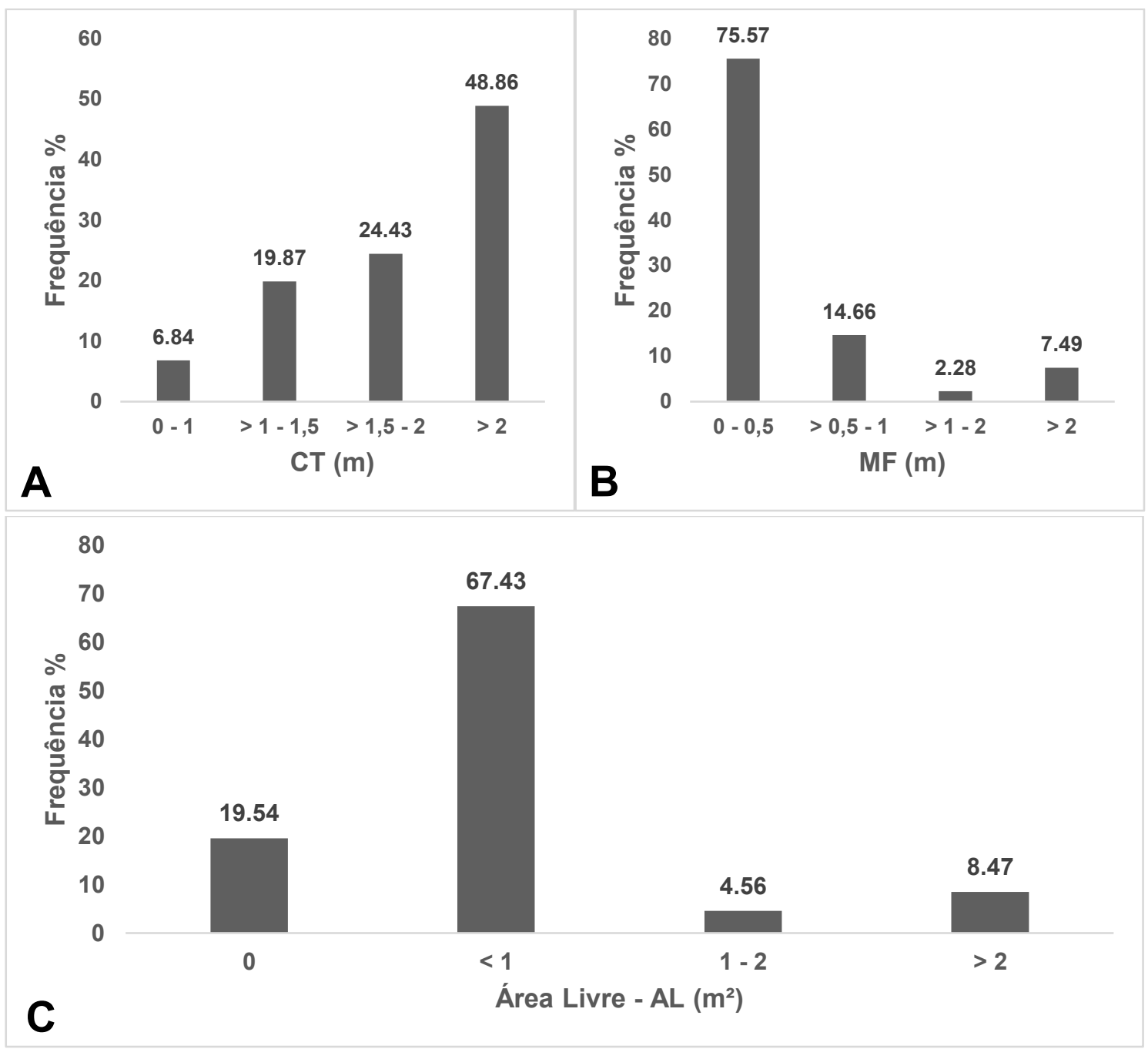

Figura 7. Frequência percentual das mensurações relacionadas ao posicionamento e a área permeável do plantio. (A) distância da construção (CT) em metros até o tronco da árvore, (B) distância do meio fio $(M F)$ em metros até o tronco da árvore e em (C) área livre permeável disponível em metros quadrados $\left(\mathrm{m}^{2}\right)$

Figure 7. Percentual frequency of the measurements related to positioning and permeable planting area. (A) distance from the curb (MF) in meters to the tree trunk, (B) construction distance (CT) in meters to the tree trunk and $(C)$ available permeable free area in square meters $\left(\mathrm{m}^{2}\right)$

Graciolli et al. (2011) identificaram que os maiores conflitos observados foram em relação ao porte inadequado ao local de implantação aliado a pequena dimensão de área livre, e a utilização de espécies exóticas em restrição de nativas, que quando utilizadas agregam valor de diversidade a paisagem. Esses conflitos podem ser resolvidos, possivelmente, com o conhecimento da população acerca do desenvolvimento das espécies arbóreas nativas e 
exóticas, salientando-se a importância da educação ambiental perante a sociedade, uma vez que a mesma pode ser considerada como uma das responsáveis pela melhoria da qualidade de vida da população e promover a mudança de valores, posturas e atitudes, sendo necessário integrar suas ações aos aspectos ecológicos, políticos, culturais e éticos.

A observação dos danos físicos foi realizada para a identificação de podas mal conduzidas, presença de troncos danificados e exposição da madeira devido à má cicatrização por possíveis injurias. Na área pouco menos da metade dos exemplares, 49,19\% ( $\mathrm{N}=151)$ apresentavam algum dano físico relacionado à poda (figura 8). A necessidade de realização de poda sempre foi sugerida em casos que a copa estava em conflitos com a fiação elétrica, edificações, iluminação, área de passeio, sinalização de trânsito ou com outras árvores. Assim indicou-se que $27,69 \%(N=85)$ necessitavam de podas. A remoção do espécime sempre foi sugerida em $7,82 \%$ ( $N=24)$ dos casos, quando observada a morte iminente do vegetal, apresentando estágio de fitossanidade ruim ou com risco iminente de queda.

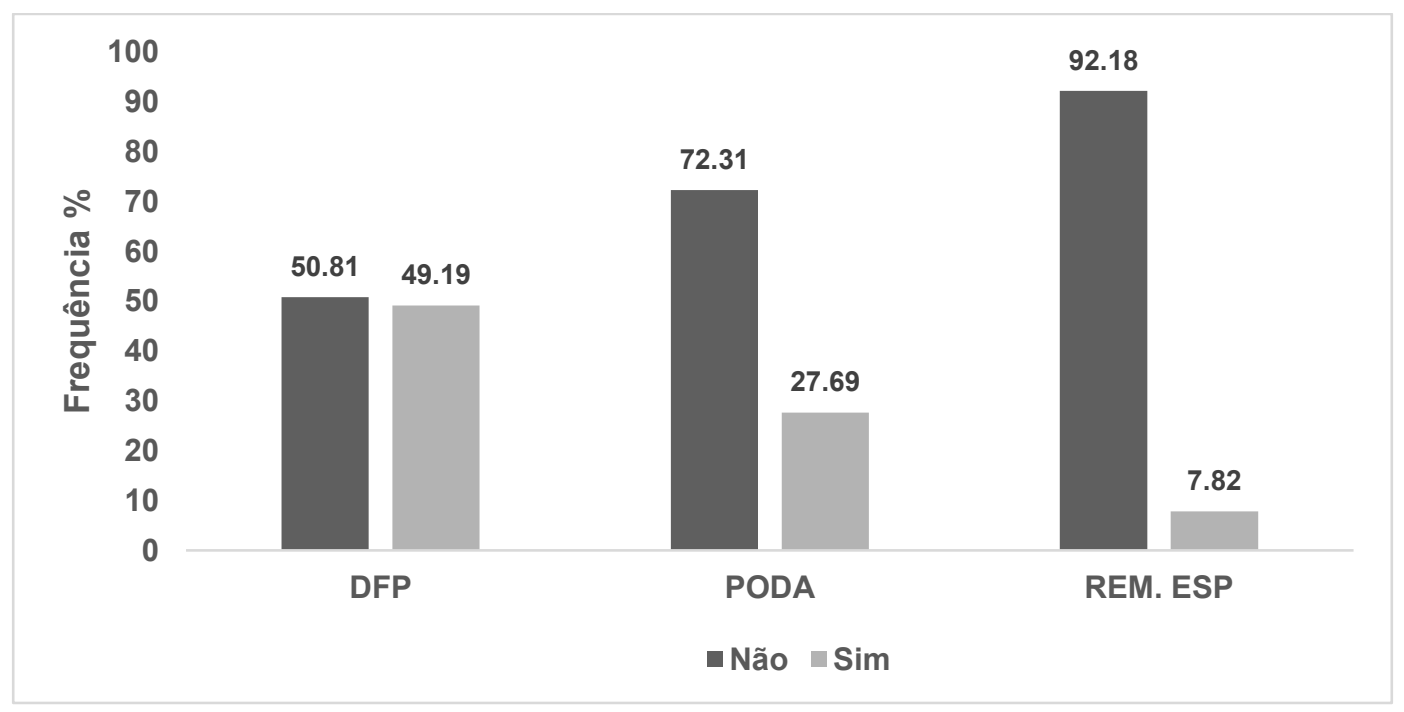

Figura 8. Frequência percentual das variáveis relacionadas ao manejo como dano físico causado por podas (DFP), necessidade de poda (PODA) e remoção do espécime (REM. ESP)

Figure 8. Percentual frequency of management-related variables such as physical damage caused by pruning (DFP), need for pruning (PODA) and removal of the specimen (REM. ESP)

Seguindo as orientações de Sampaio e Angelis (2008), as árvores cadastradas em condições ruins não foram consideradas como destinadas para remoção, pois a condenação de uma árvore só pode ser feita por profissional habilitado, mas com certeza, a classificação feita em campo indica, de forma eficaz, que esses indivíduos têm prioridade nas vistorias para remoção, por apresentarem bons indicadores de uma condição inadequada para sobrevivência no agressivo ambiente urbano. 
A fragilidade de um vegetal pode tornar-se mais expressivas nos ambientes urbanos, e por isso, podas mal realizadas pode exigir uma recuperação mais dispendiosa, expondo o tronco ao desenvolvimento de doenças, causando danos físicos de difícil reversão. As podas nas mudas plantadas, segundo o Manual Técnico de Arborização Urbana de São Paulo, deverão ser realizadas com a retirada dos ramos laterais ou "ladrões" da muda (poda de formação) e remoção de galhos secos ou doentes, a poda de limpeza (SÃO PAULO, 2005).

A poda é uma das atividades de manejo mais praticadas na arborização das cidades. $O$ ideal seria planejar o plantio, de modo que não houvesse necessidade de se praticar tantas podas, reduzindo-se significativamente o número de podas praticadas, economizando recursos que poderiam ser destinados para outras necessidades de manutenção da arborização. A vantagem em se ter este dado é expressa através da maior segurança nas tomadas de decisão no manejo, o que possibilita reduzir ou evitar inúmeros conflitos da copa do vegetal com os equipamentos e serviços urbanos (SILVA; PAIVA; GONÇALVES, 2017).

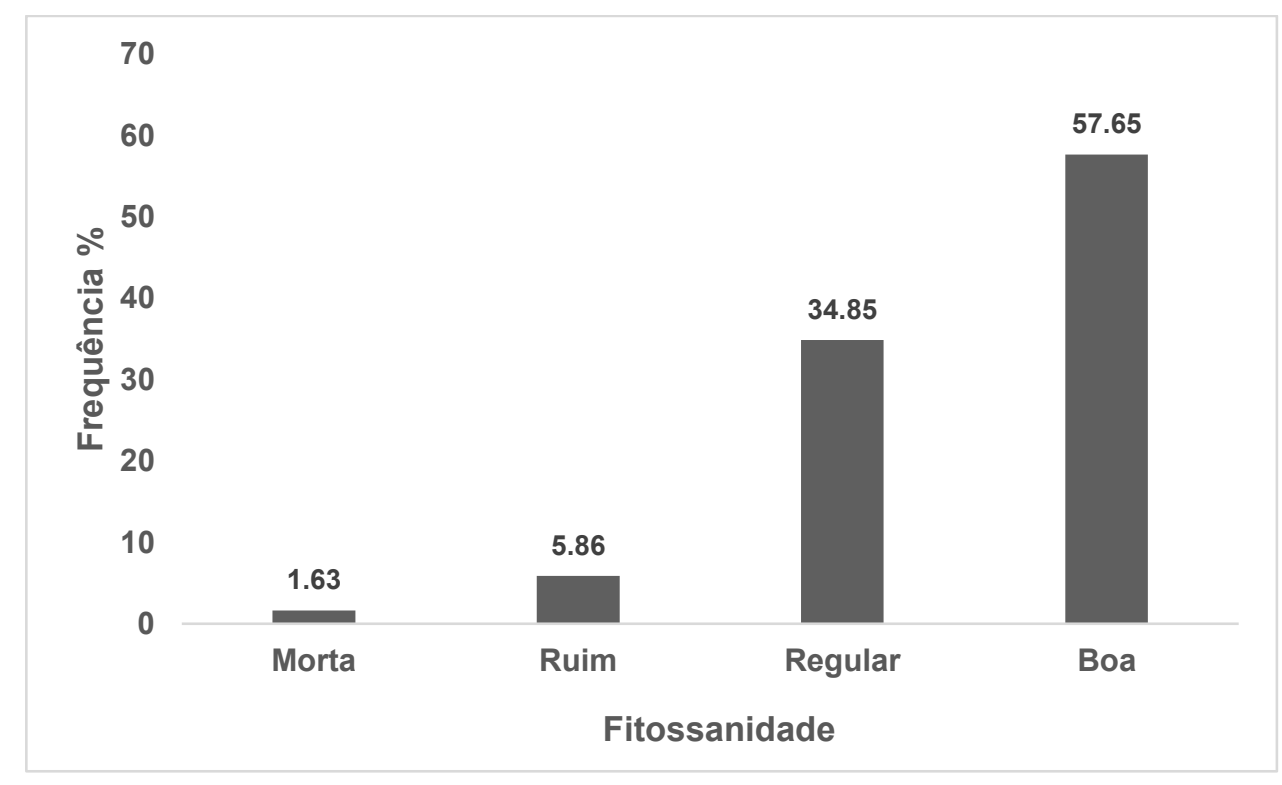

Figure 9. Percentual frequency of the qualitative parameters of plant health Figura 9. Frequência percentual dos parâmetros qualitativos de fitossanidade

De modo geral, as espécies inventariadas apresentaram um bom estado em relação a fitossanidade, com presença de poucos danos e/ou pragas (figura 9). A baixa qualidade fitossanitária muitas vezes estava relacionada a realização de podas inadequadas ou drásticas, ausências de áreas livres permeáveis e a escolha de espécies com portes incompatíveis com os equipamentos urbanos (LESSI; BATAGHIN; PIRES, 2017b). De acordo com a figura 2, uma árvore vigorosa e sem a presença de pragas ou injúrias foi classificada como boa, representando $57,65 \%(N=177)$ dos indivíduos inventariados, $34,85 \%(N=107)$ foram classificados como regulares pois apresentavam algumas injúrias decorrentes de podas mal sucedidas mas ainda 
sem a presença de doenças ou pragas, 5,86\% ( $N=18)$ estavam que um estágio ruim de conservação, com a presença de ambos problemas fitossanitários (injúria e pragas/doenças) e $1,63 \%(N=5)$ apresentavam morte iminente no momento da realização do inventário.

Em indivíduos do gênero Handroanthus sp. Mattos (Ipês), apesar de nativas, foram observados a presença de erva-passarinho em quantidades significativas para influenciarem sua fitossanidade. Sampaio e Angelis (2008) citam que a presença da erva-de-passarinho é classificada como grave quando tomava mais de $50 \%$ da copa, sendo considerada como um sintoma claro de árvores estressadas.

Dentre os argumentos que justificam a prioridade do plantio de espécies nativas em detrimento das exóticas na arborização urbana, está na sua capacidade em desenvolver de mecanismos de defesas, conferindo resistência à praga e doenças da região, a sua importância como alimento e abrigo para a fauna nativa e de suporte para epífitas que as utilizam, permitindo, de certa forma, a manutenção de processos coevolutivos entre as diferentes espécies vegetais, seus polinizadores, dispersores e seu ambiente físico. Além disso, possuem uma relação bem estabelecida entre os nutrientes disponíveis e necessários para as árvores, pela sua adaptação às condições locais. (LESSI; BATAGHIN; PIRES, 2017b).

\section{CONCLUSÕES}

A maior parte dos indivíduos observados neste estudo foram arbóreos (91,96\%). Em relação ao porte, os indivíduos (80\%) apresentaram diâmetro à altura do peito de até $40 \mathrm{~cm}$ e no máximo 5 metros de altura (cerca de $53 \%$ ), com a primeira bifurcação em até 1,5 metros de altura (65\%), no entanto, este trabalho indicou a existência de baixo índice de conflitos da vegetação com os outros elementos urbanos (danificação de calçadas pelo crescimento de raízes, com a fiação elétrica, edificações, iluminação, área de passeio, sinalização e com outras árvores). Quanto as relações entre a arborização e os elementos uranos, nas vias a arborização apresentou distanciamento regular entre as construções ( $72 \%$ com até 2 metros) e com o meio fio ( $75 \%$ com $0,5 \mathrm{~m}$ ou mais de área livre); a área permeável média foi superior a $0,33 \mathrm{~m}^{2} \mathrm{em}$ cerca de $80 \%$ dos indivíduos. A análise dos dados qualitativos mostrou danos físicos a poda em $50 \%$, necessidade de poda em quase $28 \%$ e remoção do espécime quase $8 \%$ dos casos. $A$ fitossanidade manteve-se entre boa e regular em mais de $90 \%$ dos indivíduos.

A destinação de espaço adequado para área livre permeável mostra-se favorável para a prevenção de quebra de calçadas, conservação da fitossanidade do vegetal e infiltração de água pluvial. Assim, há necessidade de maior orientação no momento de construção de canteiros, incentivos para novos plantios, principalmente em áreas próximas a cursos hídricos, e 
implantação do "espaço árvore" sugerido no Projeto Piloto de Floresta Urbana para potencializar a percolação.

Este trabalho indica a necessidade de manejo adequado construindo-se o Plano Diretor de Arborização Urbana de Jaboticabal-SP com as devidas orientações, especialmente sobre a seleção de espécies adequadas e procedimentos de plantio e manejo. Falhas no manejo da arborização urbana podem diminuir a estimativa de vida dos espécimes vegetais. A destinação de espaço adequado para área livre permeável mostra-se favorável para a prevenção de quebra de calçadas, conservação da fitossanidade do vegetal e infiltração de água pluvial. Assim, há necessidade de maior orientação no momento de construção de canteiros, incentivos para novos plantios, principalmente em áreas próximas a cursos hídricos, e implantação do espaço árvore sugerido no Projeto Piloto de Floresta Urbana para potencializar a percolação.

É necessário também que o diagnóstico da arborização urbana seja realizado de forma constante para que se consiga prever e constatar irregularidades precocemente, aumentando as chances de reversão dos impactos e recuperação ambiental, assim como, o desenvolvimento de pesquisas científicas para melhor aplicabilidade no município. De forma geral, a área selecionada para a realização do inventário de arborização urbana apresenta baixo índice de conflitos e questões relacionadas à manejo, e localização estratégica para a conexão de trechos adensados de arborização urbana, parâmetros que indicam potencial para a implantação de um corredor ecológico urbano e, assim, a consolidação do Projeto Piloto de Floresta Urbana para que se consiga a interligação de áreas verdes, como preconizado pelo Programa Município Verde Azul do Estado de São Paulo.

\section{AGRADECIMENTOS}

Agradecemos à toda a equipe da Fatec Nilo de Stéfani de Jaboticabal, SP, que forneceu todo o apoio necessário para que esse trabalho tornasse realidade.

\section{REFERÊNCIAS}

ANDRADE, M. N. M. M; JERONIMO, C. E. M. Diagnóstico da arborização do espaço urbano da cidade de João Pessoa, PB. Revista Eletrônica em Gestão, Educação e Tecnologia Ambiental, Santa Maria - RS, v. 19, n. 3, p. 194-208, 2015.

ANDREATTA et al. Análise da arborização no contexto urbano de avenidas de Santa Maria, RS. Revista da Sociedade Brasileira de Arborização Urbana, Piracicaba - SP, v.6, n.1, p. 36-50, 2011. 
BACKES, F. A. A. L.; GIRARDI, L. B.; NEUHAUS, M.; BELLÉ, R. A.; SCHWAB, N. T.; PEITER, M. X. Caracterização das espécies utilizadas na arborização urbana em Silveira Martins, RS. Revista Brasileira de Horticultura Ornamental, Campinas - SP, v. 17, n.2, p.167-174, 2011.

BASSO, J. M.; CORREAA, R. S. Arborização Urbana e Qualificação da Paisagem. Paisagem e Ambiente: Ensaios, São Paulo - SP, n. 34, p. 129-148, 2014.

BENATTI, D. P. et al. Inventário arbóreo-urbano no município de Salto de Pirapora, SP. Revista Árvore, Viçosa - MG, v. 36, n. 5, p. 887-894, 2012.

BIONDI, D. Floresta urbana. Curitiba: O Autor; 2015. 202 p.

BRUMMITT R. K.; POWELL C. E. Authors of plant names. Royal Botanic Gardens, Kew. 1st ed., 1992. $736 \mathrm{p}$.

CEMIG - Companhia Energética de Minas Gerais. Manual de arborização. Belo Horizonte: Cemig, Fundação Biodiversitas, 2011, 112 p.

CRISPIM, D. L; SILVA, M. A.; CHAVES, A. D. C. G.; ALMEILDA, R. R. P.; FREITAS, A. J. F. Diagnóstico da arborização urbana do centro da cidade de Pombal-PB. Revista Verde Mossoró - RN, v. 9, n.1, p.191-196, jan-mar, 2014.

FIDALGO, O.; BONONI, V. L. R. Técnicas de coleta, preservação e herborização de material botânico. Instituto de Botânica, São Paulo - SP. 1989. 61 p.

GOOGLE. Google Earth Pro. Versão 7.3.3.7699. Disponível em: <https://www.google.com.br/earth/download/gep/agree.html>. Acesso em: 05 mai. 2020.

GRACIOLI, C. R. et al. Arborização do campus da Universidade Federal de Santa Maria e Conscientização da Comunidade Acadêmica. Revista Monografias Ambientais Remoa: Universidade Federal de Santa Maria, v.3, n.3, p. 421-429, 2011.

GRISE, M. M.; BIONDI, D.; ARAKI, H. A floresta urbana da cidade de Curitiba, PR. FLORESTA, Curitiba - PR, v. 46, n. 4, p. 425-438, 2016.

INSTITUTO BRASILEIRO DE GEOGRAFIA E ESTATÍSTICA (IBGE). Censo Demográfico 2010. Disponível em: < https://cidades.ibge.gov.br/brasil/sp/jaboticabal/panorama>. Acesso em: 17 fev. 2021.

LESSI, B. F.; BATAGHIN, F. A.; PIRES, J. S. R. Arborização Urbana no campus da UFSCar, São Carlos, SP: Gestão e Manejo. São Carlos-SP. 1 ed. Saarbrücken, Germany: Novas Edições Acadêmicas, 2017a. v. 1. 109 p.

LESSI, B. F.; BATAGHIN, F. A.; PIRES, J. S. R. Diversity and distribution of trees on the Federal University of São Carlos Campus, Brazil: implications for conservation and management. Revista da Sociedade Brasileira de Arborização Urbana, Piracicaba - SP, v. 12, p. 92-104, 2017b.

MILANO, M. S. Avaliação quali-quantitativa e manejo da arborização urbana: exemplo de Maringá-PR. Curitiba, 1988. 136 f. Tese (Doutorado em Ciências Florestais) - Faculdade de Ciências Agrária da Universidade Federal do Paraná, Curitiba, 1988. 
PEREIRA, V. H. C; CESTARIO, L. A. Corredores ecológicos no Brasil: avaliação sobre os principais critérios utilizados de áreas potenciais. Caminhos de Geografia, Uberlândia - MG, v. 17, n. 58, p. 1-17, 2016.

OLIVEIRA, R. A.; SILVA, D. C. C.; SIMONETTI, V. C.; STROKA, E. A. B.; SABONARO, D. Z. Proposição de Corredor Ecológico entre duas Unidades de Conservação na Região Metropolitana de Sorocaba. Revista do Departamento de Geografia, São Paulo - SP, v. 32, p. 61-71, 2016.

SAMPAIO, A. C. F.; ANGELIS, B. L. D. Inventário e Análise da Arborização de Vias Públicas de Maringá-PR. Revista da Sociedade Brasileira de Arborização Urbana, Piracicaba - SP, v.3, n.1, p. 37-57, 2008.

SÃO PAULO. Manual Técnico de Arborização Urbana. São Paulo: Secretaria do Verde e do Meio Ambiente. 2 ed., 2005, 48 p.

Piloto Floresta Urbana. São Paulo: Secretaria de Meio Ambiente do Estado de São Paulo, 2011. Disponível em: http://arquivos.ambiente.sp.gov.br/municipioverdeazul/2011/11/ Piloto-de-Floresta-Urbana.pdf. Acesso em: 17 fev. 2021.

SILVA, A. G; GONÇALVES, W.; PAIVA, H. N. Avaliando a arborização urbana. Viçosa: Aprenda Fácil, 2017. 296 p.

SILVA, S. T.; SOUSA, B. H. Diagnóstico da arborização urbana do município de Guarabira Paraíba. Paisagem e Ambiente: Ensaios, São Paulo - SP, n. 41, p. 167-184, 2018. 